\title{
Formulation and Evaluation of Herbal Shampoo Containing Extract of Grewia Optiva
}

\author{
Archana Dhyani, Nardev singh, Vijay kumar
}

\begin{abstract}
Synthetic shampoos are responsible for undesirable properties among customers. An additional method used to decrease the use of artificial components is by adding natural component. of Grewia optiva bark was selected on the basis of its surfactant property. The aim of this research is to formulate a hair shampoo with Grewia optiva bark with importance on protection and efficiency. The formulation was evaluated for different parameters. It was found that the product has good foaming capacity and capable of reduction of surface tension .
\end{abstract}

Keywords: Shampoo, Grewia optiva, surfactant, surface tension, cleansing action.

\section{INTRODUCTION}

The Indian word capna meaning "push," which was extended to point out the action of washing hairs. ${ }^{1}$ Shampoo is a aesthetic product used to dirt free the hair and scalp, and havea number of types of constituents in its formulation such as surfactants, solvents, coloring agents, $\mathrm{pH}$ adjustments, preservatives, and so on. ${ }^{2}$ It consists of surfactant either in liquid or solid which eliminate theoil of hairs, removes dirt and dustwith no adverse effect on the hair, scalp or wellbeing of the user. ${ }^{3}$ Shampoo are used regularlyfor organizing the hair and its surroundings. In the early 1900's soap is only available for cleaning of hair. ${ }^{4}$ Shampoos are thick and can be used in the form of liquid or semi-soild forms. ${ }^{5}$ Shampoos are divided into different typesas per their use. ${ }^{6}$ The drawback of using the artificial shampoo is that they causes rough hairs with loss and effects eyes as well. Herbal shampoos are favored over synthetic shampoos because of their low side effects and their natural benefits. ${ }^{7}$

The aim of the research article is to formulateand evaluate the herbal shampoo of Grewia optivacommonly known as Bhimalin Uttarakhand .The tree is found at an altitude of 2000 meter. It found in the mountainarea. ${ }^{8}$ The bark of Bhimal have saponins which is responsible for the surfactant and detergency property. The shampoo was subjected to different evaluation parameters like ph, viscosity,wetting time,foam formation and cleansing action. ${ }^{9}$ Grewia optiva is used as fodder in Uttarakhand bu traditionally it is used to clean the hairsin ancient time. So, this traditional use of Grewia optiva is used to prepare the shampoo.

\section{MATERIAL \& METHODOLOGY}

2.1 Materials: The plant was obtained from hills of Uttarkashi district of Uttarakhand . The different ingredients were procured from Central Drug House Ltd.(CDH), New Delhi.

22.2Preparation of Plant Extracts: The bark of the plant were converted into powder by size reduction. Weigh about $50 \mathrm{gm}$ of powder and add $200 \mathrm{ml}$ methyl alcohol in it . The sample is kept in dim area for 2 days at normal temperature. The sample was put into filteration by using filter medium. The filtrates obtained were exposed at $60{ }^{\circ} \mathrm{C}$ for $30 \mathrm{~min}$. so that the methanol can evaporate. Then, the filtrates were stored at $4^{\circ} \mathrm{C}$ for further use. ${ }^{4}$

2.4 Preparation Of Shampoo: For preparation of shampoo saponification is done. The different oils were mixed with potassium hydroxide for reflux condensation. The plant extract is added in it .Finally, glycerin and ethanol were added in the formulation .(Table 1)
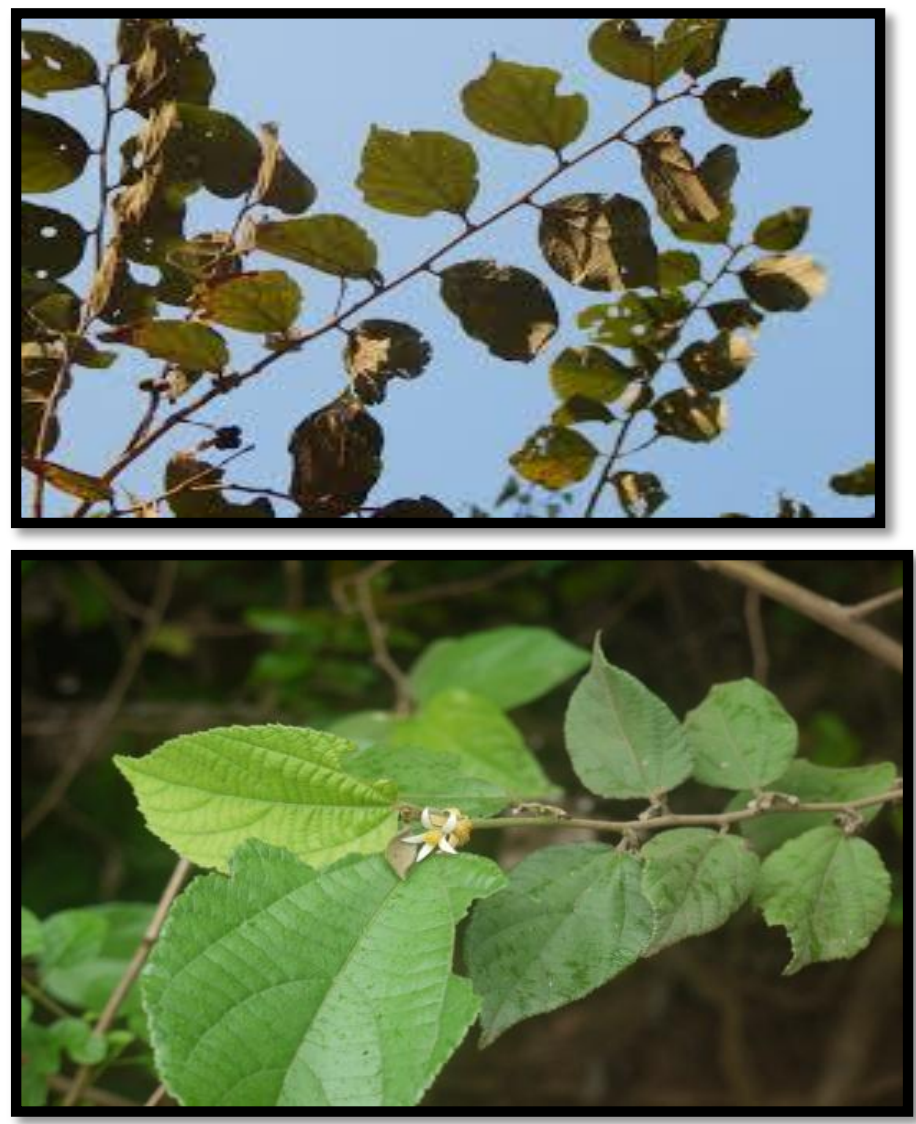

Fig1: Grewia optiva

Revised Manuscript Received on November 25, 2019.

Archana Dhyani, School of Pharmacy, Graphic Era Hill University, Dehradun, Uttarakhand, India.

Nardev Singh, School of Pharmacy, Graphic Era Hill University, Dehradun, Uttarakhand, India.

Vijay kumar, School of Allied Science, Graphic Era Hill University, Dehradun, Uttarakhand, India 
Table 1: Composition of Herbal Shampoo

\begin{tabular}{|c|c|c|c|c|c|}
\hline Ingredients(\%w/w) & $\mathbf{F}_{\mathbf{1}}$ & $\mathbf{F}_{\mathbf{2}}$ & $\mathbf{F}_{\mathbf{3}}$ & $\mathbf{F}_{\mathbf{4}}$ & $\mathbf{F}_{\mathbf{5}}$ \\
\hline $\begin{array}{c}\text { Potassium } \\
\text { Hydroxide }\end{array}$ & 3 & 4 & 3 & 4 & 3 \\
\hline Olive Oil & 2 & 3 & 2 & 3 & 2 \\
\hline Castor Oil & 1 & 2 & 1 & 2 & 3 \\
\hline Coconut Oil & 5 & 10 & 15 & 5 & 10 \\
\hline Glycerin & 2 & 2 & 2 & 2 & 2 \\
\hline Ethanol & 4 & 4 & 4 & 4 & 4 \\
\hline $\begin{array}{c}\text { Grewia optiva } \\
\text { Extract }\end{array}$ & 5 & 10 & 15 & 20 & 25 \\
\hline Distilled water q.s & 100 & 100 & 100 & 100 & 100 \\
\hline
\end{tabular}

\subsection{Evaluation Parameters}

1. Physical appearance/visual inspection: The organoleptic properties were determined by sensory organ. ${ }^{5}$ 2.pH: $\mathrm{pH}$ meter helps inpH determination .

3. Foam Formation (Shake Test): Took $20 \mathrm{ml}$ of the $2 \%$ shampoo solution in a $250 \mathrm{ml}$ measuring cylinder and the volume was noted down. The cylinder was covered and shaked 10 times. Calculate the foam produce and\% foaming capacities of all the formulations for a time period of 60 minutes. ${ }^{6}$

4. Cleaning action: For this specific quanttity of wool were treated with greasiness and then put into contact with shampoo at room temperature. The samples wsa shaked well and after specific period of time detergency percentage was calculated. $^{7}$

The formula used for calculation of detergency is :

$$
\mathrm{DP}=\mathbf{1 0 0}(1-\mathrm{T} / \mathrm{C})
$$

DP -Percentage detergency power

$\mathrm{C}$-weight of sebum in the control sample

$\mathrm{T}$-weight of sebum in the test sample.

5. Viscosity: For determination of viscosity multipoint rotational Brook field viscometer is used. ${ }^{8}$

6. Wetting time: Weighed amount of velvet is sinked into a solution of shampoo for determination of wetting time. The time in which the velvet is sinked is noted down.

7. Surface tension: It was determined by using stalagmometer. ${ }^{1}$

8. Determine percent of solid contents: A dry china dish was taken and 4 grams of shampoo is poured in it. The exact weight was noted. The dish is then put for evaporation till the whole liquid was evaporated. The amount of soild left drying was determined. ${ }^{11}$

\section{RESULTS AND DISCUSSION}

\section{Formulation of Shampoo:}

The shampoo was formulated by using the extract of Grewia optivawhich is also known as Bhimal in Uttarakhand. The plant contains saponins thus it has good detergency and cleansing property. The coconut oil olive and castor oil will acts as conditioner after washing the hairs.

1. Physical appearance/visual inspection: The color of the shampoo was found to be dark brown in color . The odor was not found to be obnoxious.

2.pH: ThepH of all formulations in the range of 5-7.The $\mathrm{pH}$ plays an important role and helps in reduction of eye irritation.
3. Foam Formation: All the shampoos have a good quality foaming capacity. The foaming capacity varies from 49 to $61 \%$. Foam produced by shampoos was uniform .Although foam formation does not have any relationship with cleansing property. But it is required for the satisfaction of the customer.It is a desirable property for the customer. Since it was believed that more foam production is associated with the high cleansing property.

4.Cleaning action: The cleaning action of all formulation was found in the range of 65 to $89 \%$ which shows that the shampoo has good quality cleansing property.The cleansing property helps to evaluate the capability to take away dirt from hairs. The formulation containing high percentage of Grewia optiva has more cleansing activity .

5.Viscosity: The shampoos must have appropriate viscosity since the viscosity is directly related to the stability of the product,shelf-life of product, ability to flow and capability to spread.

The viscosity was found in the range of 1268 to $3256 \mathrm{cP}$.

6.Wetting time : The wetting property depends on various factor like surface tension, diffusion coefficient and surface nature. The wetting time was found in the range of 198-224 sec.

7.Surface tension:The shampoo is supposed to have the property of reducing the surface tension. The prepared formulations have the capability to reduce the surface tension. The values was found to be between 14 to 28 dyne $/ \mathrm{cm}$ which shows that the prepared formulations has a good surfactant and detergency property and thus it helps in removal of dirt from hairs.

8.Determination of Solid Content : The solid content is required in the shampoo so that the shampoo cannot be wash away easily.Some amount of solids helps the shampoo to retain on the surface of hairs. But, the amount of solids should be such that it can be easily removed from the hairs. The results given in the table 2 which shows that the there is considerable amount of solids are present in the shampoo.However, the values varies from 23 to $39 \%$. 
International Journal of Engineering and Advanced Technology (IJEAT) ISSN: 2249 - 8958, Volume-8 Issue-6S4, November 2019

Table 2: Results of different formulations $\left(F_{1}\right.$ to $\left.F_{5}\right)$

\begin{tabular}{|c|c|c|c|c|c|c|c|c|}
\hline Formulations & $\begin{array}{l}\text { Physical } \\
\text { Appearance }\end{array}$ & pH & $\begin{array}{l}\text { Foaming } \\
\text { Capacity } \\
(\%)\end{array}$ & $\begin{array}{l}\text { Viscosity } \\
\text { (Cp) }\end{array}$ & $\begin{array}{l}\text { Surface } \\
\text { Tension } \\
\text { (dyne /cm) }\end{array}$ & $\begin{array}{l}\text { Wetting } \\
\text { time(sec.) }\end{array}$ & $\begin{array}{l}\text { Cleaning } \\
\operatorname{action}(\%)\end{array}$ & $\begin{array}{l}\text { Solid } \\
\text { Content }(\%)\end{array}$ \\
\hline F1 & $\begin{array}{l}\text { Brownish, no } \\
\text { smell }\end{array}$ & $6.54 \pm 0.21$ & 49.43 & $1268 \pm 0.98$ & $28.45 \pm 0.76$ & $224 \pm 0.76$ & $65.30 \pm 0.12$ & $23.41 \pm 0.38$ \\
\hline $\mathrm{F} 2$ & $\begin{array}{l}\text { Brownish, } \\
\text { no smell }\end{array}$ & $6.2 \pm 0.53$ & 46.98 & $2459 \pm 0.48$ & $14.98 \pm 0.34$ & $206 \pm 0.21$ & $71.27 \pm 0.25$ & $24.56 \pm 0.98$ \\
\hline F3 & $\begin{array}{l}\text { Brownish, } \\
\text { characteristic } \\
\text { smell of } \\
\text { extract observed }\end{array}$ & $5.89 \pm 0.67$ & 54.18 & $3458 \pm 0.92$ & $31.22 \pm 0.56$ & $219 \pm 0.31$ & $79.87 \pm 0.55$ & $27.87 \pm 0.78$ \\
\hline $\mathrm{F} 4$ & $\begin{array}{l}\text { Brownish, } \\
\text { characteristic } \\
\text { smell of } \\
\text { extract observed }\end{array}$ & $5.5 \pm 0.91$ & 57.89 & $3543 \pm 0.99$ & $25.89 \pm 0.92$ & $198 \pm 0.48$ & $85.89 \pm 0.24$ & $29.16 \pm 0.29$ \\
\hline F5 & $\begin{array}{l}\text { Brownish, } \\
\text { characteristic } \\
\text { smell of } \\
\text { extract observed }\end{array}$ & $5.9 \pm 0.79$ & 61.45 & $3876 \pm 0.49$ & $22.89 \pm 0.89$ & $210 \pm 0.65$ & $89.72 \pm 0.98$ & $32.98 \pm 0.55$ \\
\hline
\end{tabular}

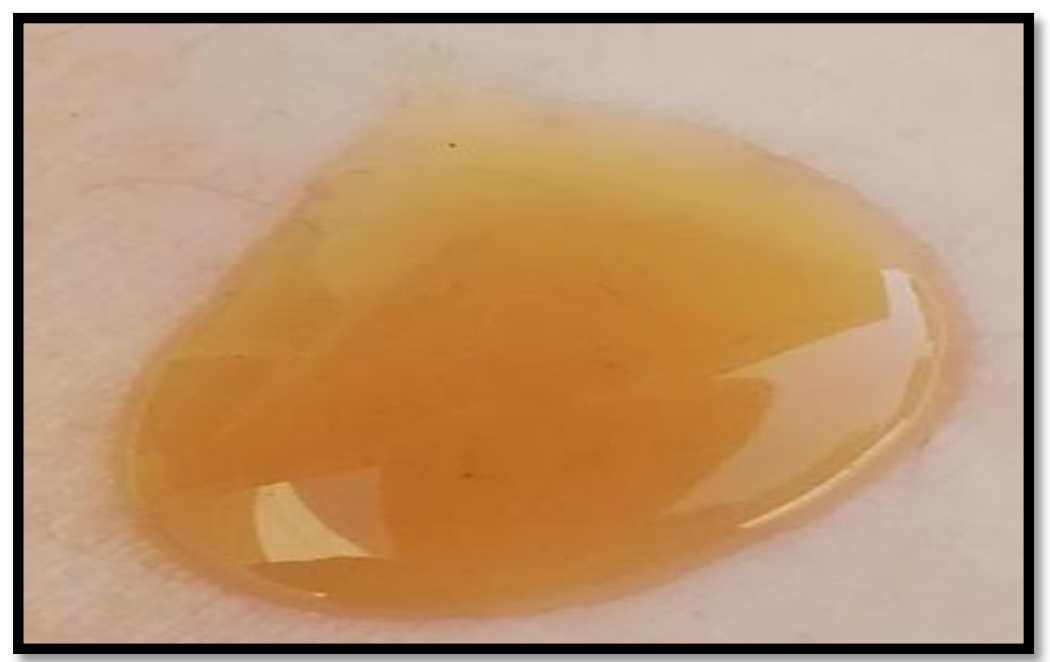

Fig 2: Formulation of herbal shampoo

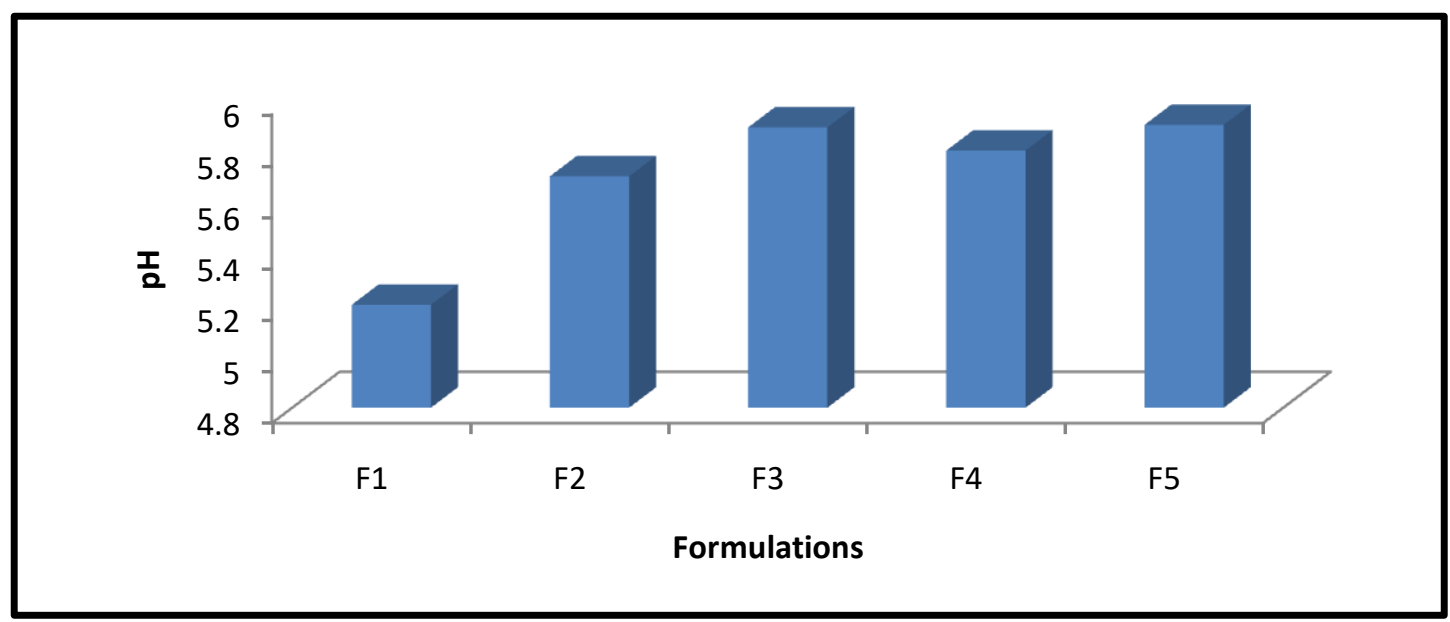

Fig 3 : Results of $\mathrm{pH}$ on different formulations

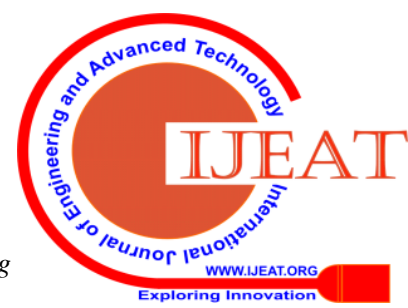




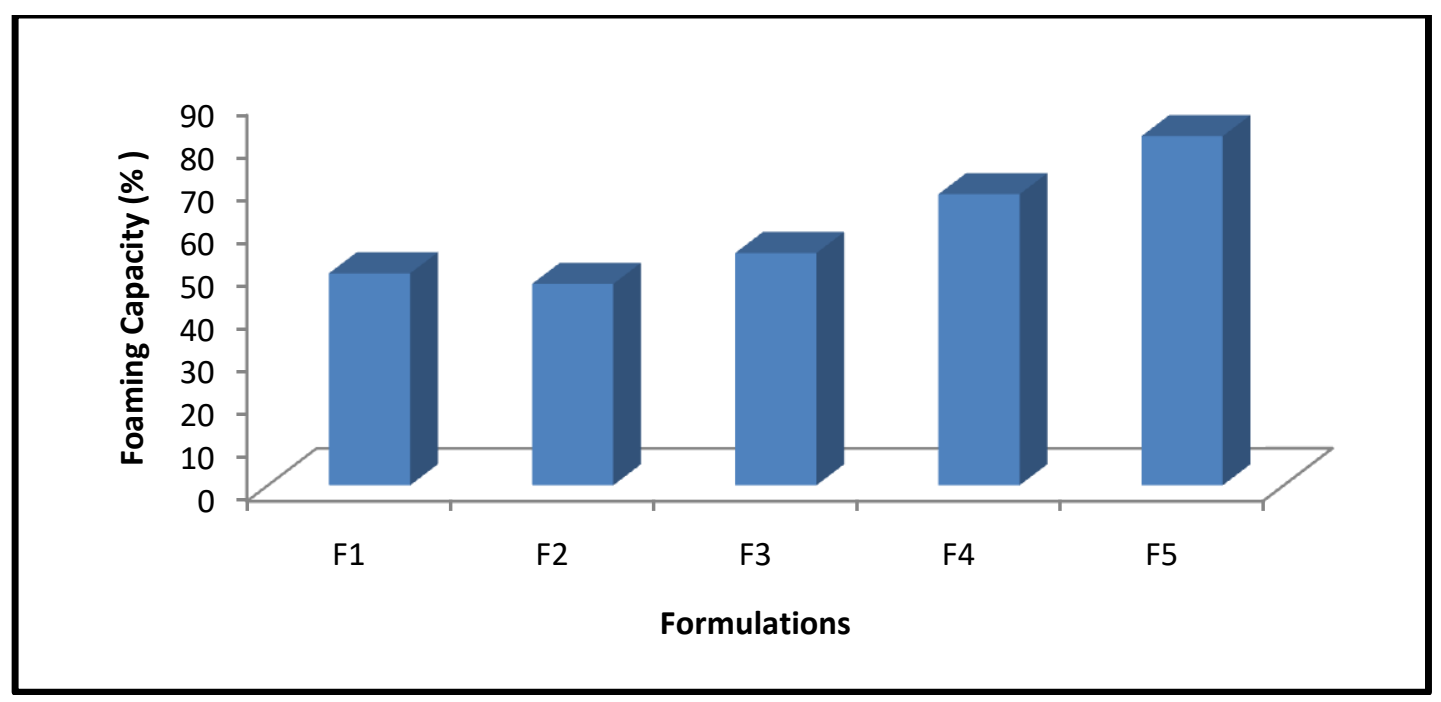

Fig 4: Results on foaming capacity (\%)on different formulations

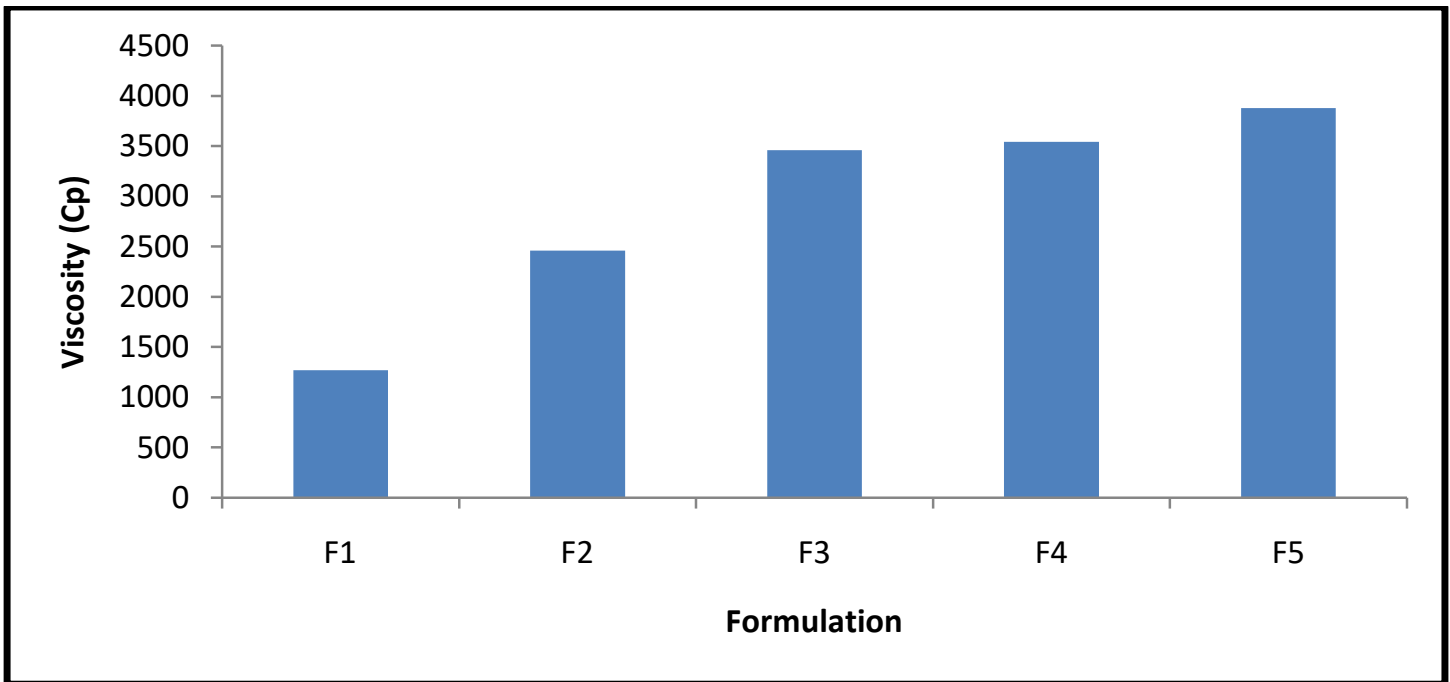

Fig 5 : Results of viscosity on different formulations

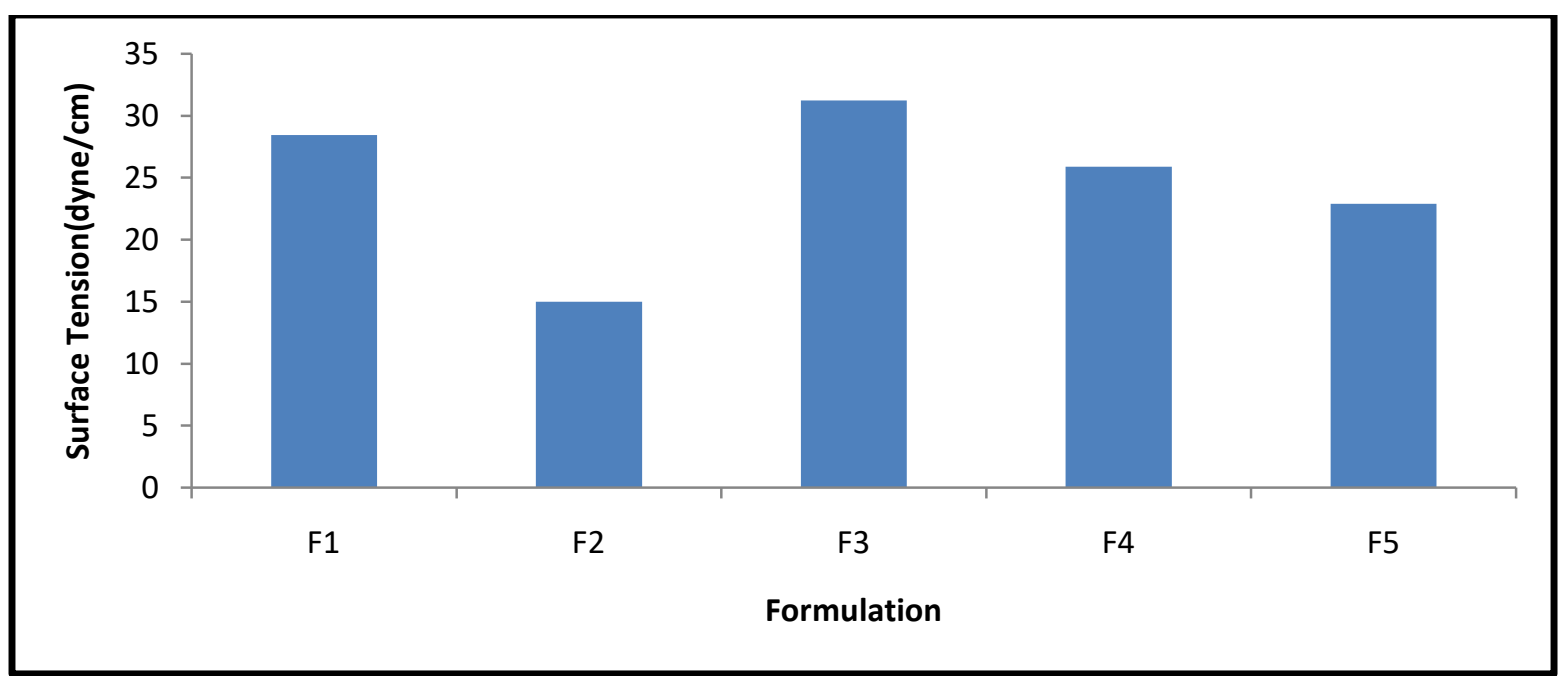

Fig 5 : Results of Surface tension on different formulations 


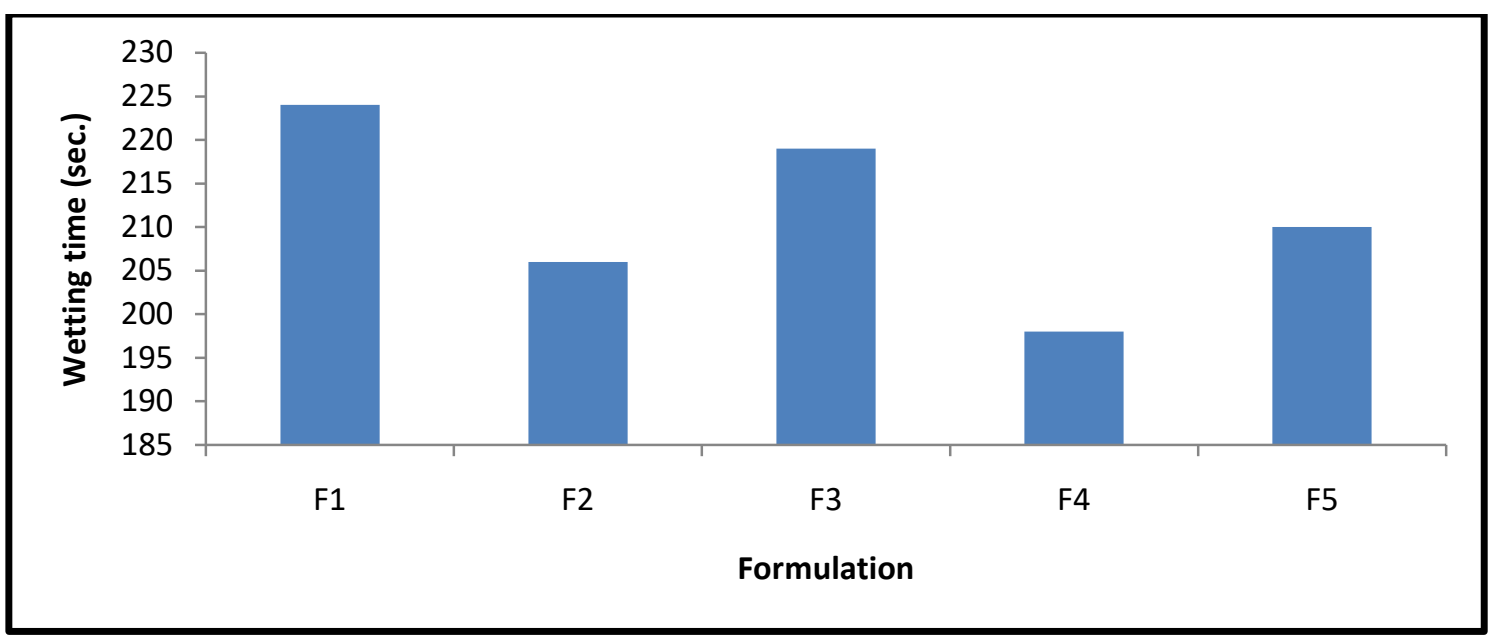

Fig 6: Results of wetting time on different formulations

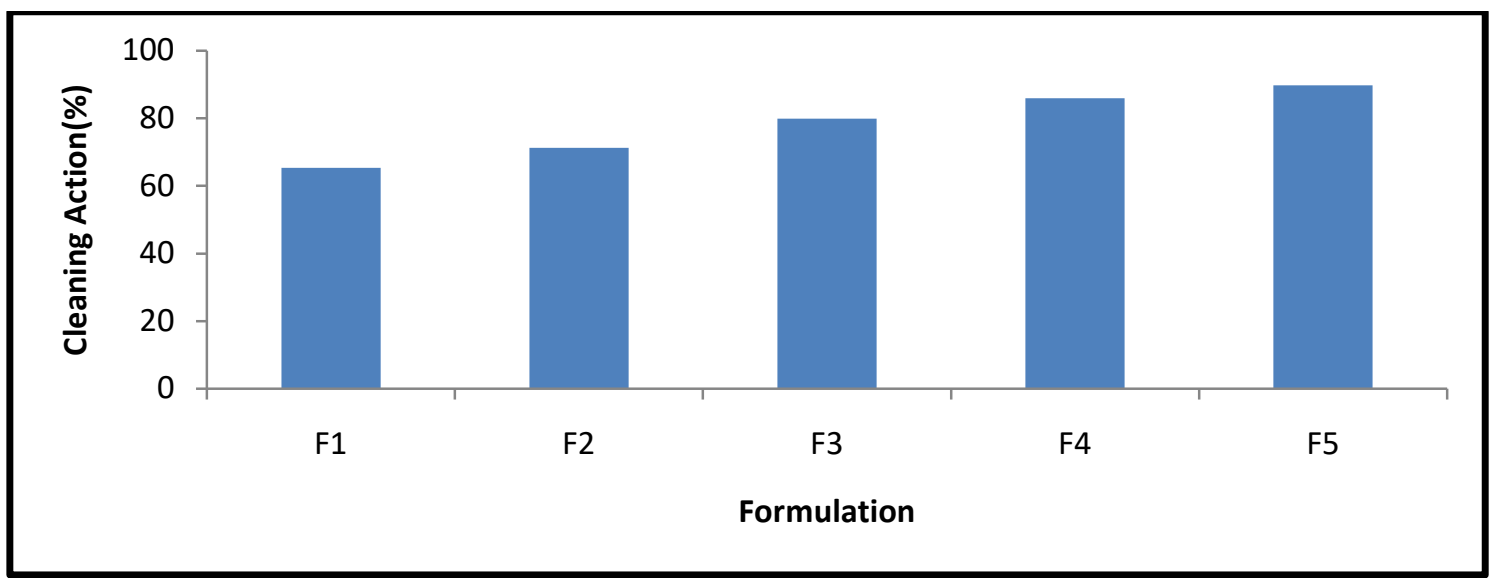

Fig 7: Results of cleaning action (\%) on different formulations

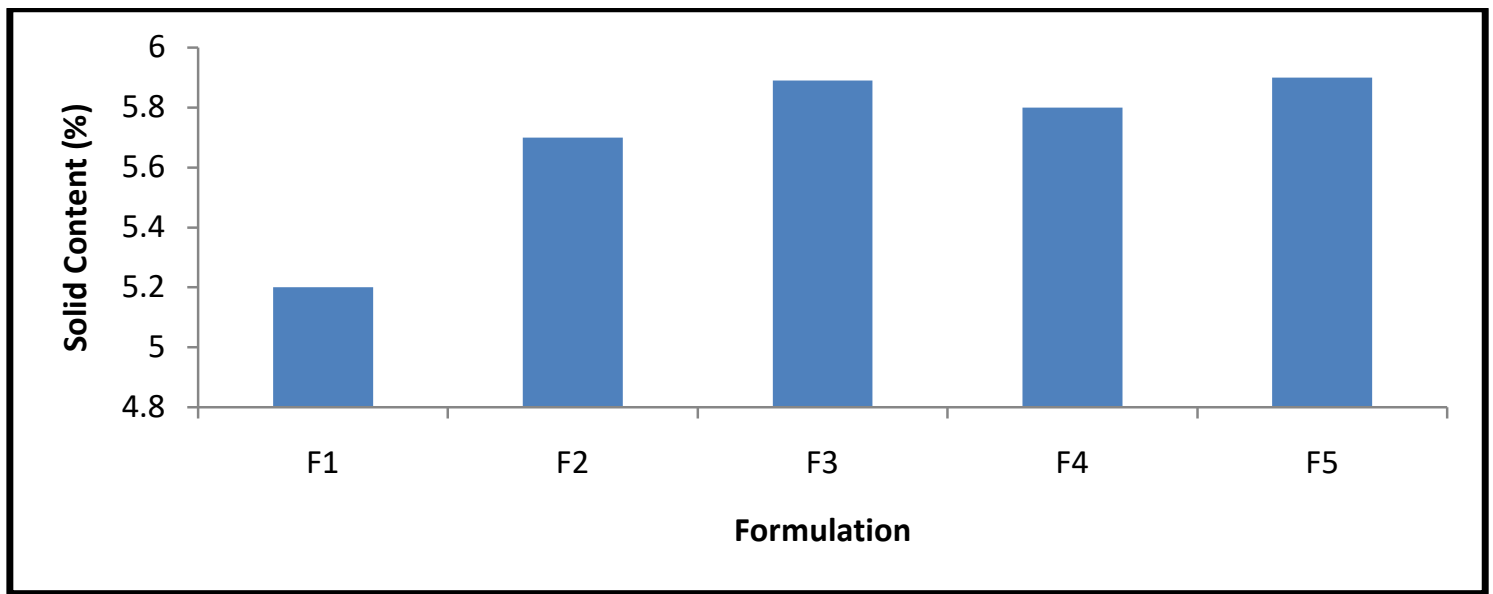

Fig 8: Results of Solid Content (\%) on different formulations

\section{CONCLUSION}

The purpose of study was formulation herbal shampoo using extract of Grewia optiva which is usually known as Bhimal in Uttarakhand .The bark of the plant was used for washing the hairs in the rural area. The study focused on the use of Grewia optiva (Bhimal) as natural surfactant in the shampoos. The shampoo is wholly prepared by using natural ingredients therefore it prevents the harm to hairs from the synthetic chemicals. Further, it will also promotes the use of Grewia optiva (Bhimal) as surfactant in National and International market.

\section{REFERENCES}

1. Bouillon C. Shampoos. Clin Dermatol 1996;14:113-21.

2. M.K. Ishii,Objective and instrumental methods for evaluation of hair care product efficacy and substantiation of claims, Hair and hair care, Marcel Dekker, Inc, New York (1997),261-302

3. Robbins CR, Interaction of shampoo and cream rinse ingredients with human hair, Chemical and physical behavior of human hair,2nd ed. New York: Springer-Verlag; 1988: 193.

4. Mohammad Azadbakht, Taha Monadi1, Zahra Esmaeili, Aroona Chabra, Naser Tavakoli, Formulation and Evaluation of Licorice Shampoo in Comparison with Commercial Shampoo,Journal of Pharmacy and Bioallied Sciences : Volume 10 issue 4 2018:208-215

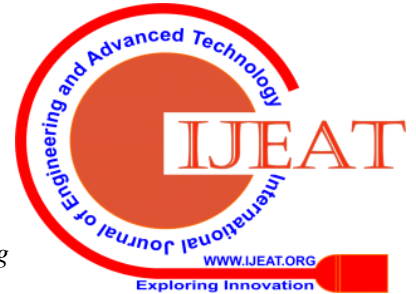




\section{Formulation and Evaluation of Herbal Shampoo Containing Extract of Grewia Optiva}

5. Riham O. Bakr, Reham I. Amer, Marwa A. A. Fayed, Tamer I. M. Ragab, A Completely Polyherbal Conditioning and Antioxidant Shampoo:A Phytochemical Study and Pharmaceutical Evaluation,Pharmacy and Bioallied Sciences,11(2) 2019 :105-115

6. Potluri, S.S.K. Asma, N. Rallapally, S. Durrivel, G.A. HarishReview on herbs used in Anti-dandruff shampoo and its evaluation parameters, Indo Am J Pharm Res, 3 (4) (2013), pp. 3266-3278)

7. Bushra T.,AlQuadeib,Rana, A.Banafa,Lama A.,AlHadhairi,Pharmaceutical Evaluation Of Different Shampoo Brands In Local Saudi Market, Saudi Pharmaceutical Journal , 26(1), 2018: 98106.

8. Mehta PC, Bhatt KC, Traditional soap \& detergents yielding plants of Uttaranchal, Indian Journal of Traditional knowledge,6(2),2007:279284.

9. Shefali Arora, Antibacterial, antifungal, antioxidant and phytochemical study on the leaves extract of Grewia optiva, Journal of Pharmacy Research 2011,4(9),3130-3132.

10. Rasha Saad Suliman, Heyam Ali , Intan Nurulain, Nik NurShamiha , Mohamad Nizam , Sri Budiasih, Cinnamon Bark Extract For The Formulation And Characterisation Of Antimicrobial Cream, International journal of Ayurveda Research, 8 (2), 2017:1-17.

11. Aghel N., Moghimipour B. and Dana R.A., Iranian Journal of Pharmaceutical Research 2007, 6(3), 167-172.

12. Prajapati Sonu, Sharma Pragya, Mr. Raghvendra Dubey, Dr. Sumeet Dwivedi, Formulation And Evalution Of Two In One Herbal Conditioning Shampoo Containing Extract Of Allium Cepa And Trigonella Foenum Graecum,World Journal of Pharmaceutical and Life Sciences, 2017, 3(2): 68-71

13. Akula Nikhil Prashant, Preparation And Evaluation Of Shampoo Powder Containing Herbal Ingredients, Asian J Pharm Clin Res, 8(1), 2015, 266-270.

14. Bushra T. AlQuadeib, Eram K.D. Eltahir,Rana A. Banafa, and Lama A. Al-Hadhairi, Pharmaceutical evaluation of different shampoo brands in local Saudi market,Saudi Pharm J. 2018 ,26(1): 98-106.

15. Krunali T., Dhara P. Evaluation Of Standards Of Some Selected Shampoo Preparation. World J. Pharm. Pharm. Sci. 2013;2:36223630.

16. Kumar Ashok and Roshan Mali Rakesh, Evaluation Of Prepared Shampoo Formulations And To Compare Formulated Shampoo With Marketed Shampoos, International Journal of Pharmaceutical Sciences Review and Research 3(1), 2010;:1-7.

17. Reddy V.Sarovar, Kumar Reddy D.Jeevan , Velu M.G, Formulation and Evaluation of Antidandruff Shampoo, Journal of Pharmacy Research, 2016,10(11),700-702 . 